\title{
Change in delay of atrioventricular conduction after radiofrequency catheter ablation for atrioventricular nodal re-entry tachycardia
}

\author{
T A Simmers, E F D Wever, F H M Wittkampf, R N W Hauer
}

\begin{abstract}
Objective-To monitor atrioventricular conduction after radiofrequency ablation for atrioventricular nodal re-entry tachycardia.

Design-Measurement of PR interval from 12 lead surface electrocardiograms before; at $0,24,48,72$, and 96 hours; and at 1 and 6 months after radiofrequency ablation.
\end{abstract}

Patients-40 consecutive patients with atrioventricular nodal re-entry tachycardia. The anterior approach was used in $\mathbf{2 3}$ patients, the posterior approach in 17.

Results-With the anterior approach the PR interval increased significantly and progressively until 48 hours after ablation (maximum 282 (SD 62.2) ms, before ablation $142(29.5)$ ms; $P<0.0001)$. Up to 96 hours no further change was observed, but one month after ablation the PR interval had decreased to a value not significantly different from that 24 hours after the procedure $(231(51 \cdot 2) \mathrm{ms})$. In one patient total atrioventricular block developed 24 hours after an uncomplicated procedure and a permanent pacemaker was implanted. With the posterior approach the $\mathbf{P R}$ interval increased slightly in the first 24 hours (156 (22.7) ms, before ablation $144(21 \cdot 2) \mathrm{ms} P=$ $0.004)$, but it had returned to preablation values at 1 month. One patient developed second degree atrioventricular block during the first 24 hours after ablation, despite delivery of all radiofrequency pulses posterior to Koch's triangle at sites without His bundle deflection. PR intervals at 6 months did not differ significantly from the values at 1 month.

Conclusion-After the anterior approach the progressive delay in atrioventricular conduction up to 48 hours after radiofrequency ablation for atrioventricular nodal re-entry tachycardia warrants continuous in hospital monitoring of patients for at least two days after the procedure.

Heart-Lung Institute University Hospital Utrecht, The Netherlands T A Simmers E F D Wever F H M Wittkampf R N W Hauer

Correspondence to: Dr T A Simmers, Department of Cardiology, Heart-Lung Institute, E03.406, University Hospital Utrecht, PO Box 85500,3508 GA Utrecht The Netherlands.

Accepted for publication 16 November 1994
Recently radiofrequency ablation has proved to be a safe and effective treatment for atrioventricular nodal re-entry tachycardia. Two approaches have been described, ablation applied anteriorly in Koch's triangle eliminating fast pathway conduction ${ }^{1-4}$ and that applied posteriorly near the ostium of the coronary sinus eliminating slow pathway conduction..$^{5-7}$ Although the anterior approach leads to prolongation of the atrioventricular interval, close monitoring of atrioventricular conduction during radiofrequency ablation by both approaches is well recognised to be mandatory to prevent inadvertant loss of $1: 1$ conduction or a haemodynamically undesirable extreme lengthening of the interval. On the other hand, both information and consensus are lacking regarding monitoring of atrioventricular conduction after ablation. Dynamic factors such as local oedema and tissue retraction during scar formation might lead to increasingly delayed atrioventricular conduction even after ablation.

\section{Patients and methods}

ABLATION PROCEDURE

Forty consecutive patients undergoing radiofrequency ablation for the typical form of atrioventricular nodal re-entry tachycardia were included in the study. The disease was diagnosed during baseline electrophysiological studies, as previously described. ${ }^{89}$ Ablation was performed in the same session as the baseline study, after patients had stopped taking antiarrhythmic drugs for at least five half lives. The anterior approach was used primarily in the first 20 cases and in a further three because of failure of the posterior approach. Ablation sites were reached by positioning the catheter at the site of maximum His bundle deflection and withdrawing under clockwise torque until the His electrogram measured $<150 \mu \mathrm{V}$ and the ratio of the amplitude of atrial to ventricular signals was greater than 1 .

The posterior approach was used alone in the remaining 17 cases. After the ostium of the coronary sinus had been identified the catheter was moved along the tricuspid annulus to positions showing fragmented atrial activation, or slow potentials as previously described, ${ }^{610}$ and a ratio of the amplitude of atrial to ventricular signals of less than or equal to 1 . If atrioventricular nodal re-entry tachycardia remained inducible after at least two deliveries of full power and duration the catheter was repositioned at sites successively more anterior along the tricuspid annulus. Care was taken to remain at least $5 \mathrm{~mm}$ distant from the site of maximum His bundle deflection. 
Radiofrequency current was delivered using a standard steerable $4 \mathrm{~mm}$ tip 7 French electrode catheter, generally during atrial stimulation at a cycle length of $500 \mathrm{~ms}$. Output was started at around $10 \mathrm{~W}$, being increased gradually until a maximum $25 \mathrm{~W}$. Pulses were delivered up to $40 \mathrm{~s}$ at maximum output or until a sudden rise of impedance occurred, indicating coagulum formation; the catheter became dislodged; or a non-conducted complex or prolonged junctional rhythm $(>5 \mathrm{~s})$ occurred, prohibiting assessment of atrioventricular conduction. Output was kept stable during junctional rhythm and was increased further only after intact atrioventricular conduction had been confirmed. Procedure end points were non-inducibility of atrioventricular nodal re-entry tachycardia or occurrence of second or third degree atrioventricular block. Inducibility was also assessed during continuous intravenous infusion of isoprenaline at a dose causing an increase in heart rate in sinus rhythm of at least $30 \%$ (1-4 $\mu \mathrm{g} / \mathrm{min})$.

\section{ASSESSMENT OF ATRIOVENTRICULAR CONDUCTION}

To assess the delay in conduction caused by radiofrequency ablation $P R$ intervals were measured from a 12 lead surface electrocardiogram before ablation (on admission) and at $0,24,48,72$, and 96 hours and at 1 month and 6 months after. As most patients who had posterior ablation were discharged from hospital three days after treatment PR intervals for this subgroup were not available at 96 hours.

\section{STATISTICAL ANALYSIS}

Values are expressed as means (SD). Comparative statistics were performed using a two tailed paired Student $t$ test. Significance was inferred from a $P$ value $\leqslant 0 \cdot 05$.

\section{Results}

\section{OUTCOME OF ABLATION}

Atrioventricular nodal re-entry tachycardia could not be induced in any patients who had atrioventricular conduction on leaving the electrophysiological laboratory. After an overall follow up time of $21 \cdot 8(14 \cdot 1)$ months (range 2-62) no recurrences had occurred in the group who were treated initially by the poste-

Mean (SD) PR intervals (ms) before and after $R F$ ablation for atrioventricular nodal re-entry tachycardia by anterior or posterior approach

\begin{tabular}{|c|c|c|c|c|}
\hline \multirow[b]{2}{*}{ Time relative to ablation } & \multicolumn{2}{|c|}{ Anterior approach $(n=23)$} & \multicolumn{2}{|c|}{ Posterior approach $(n=17)$} \\
\hline & $P R$ interval & $P$ value ${ }^{\star}$ & $P R$ interval & $P$ value \\
\hline $\begin{array}{l}\text { Before } \\
\text { After: }\end{array}$ & $142(29 \cdot 5)$ & & $144(21 \cdot 2)$ & \\
\hline $\begin{array}{l}0 \\
24 \text { Hours } \\
48 \text { Hours } \\
72 \text { Hours } \\
96 \text { Hours } \\
1 \text { Month } \\
6 \text { Months }\end{array}$ & $\begin{array}{l}200(46 \cdot 7) \\
259(64 \cdot 0) \\
282(62 \cdot 2) \\
271(69 \cdot 4) \\
275(51 \cdot 7) \\
231(51 \cdot 2) \\
225(52 \cdot 1)\end{array}$ & $\begin{array}{l}0.00017 \\
0.0004 \\
0.006 \\
>0.05 \\
>0.05 \\
0.0013 \\
>0.05\end{array}$ & $\begin{array}{l}147(23 \cdot 4) \\
156(22 \cdot 7) \\
162(22 \cdot 7) \\
168(23 \cdot 2) \\
\text { NA } \\
152(17 \cdot 9) \\
151(26 \cdot 3)\end{array}$ & $\begin{array}{l}>0.05 \\
0.033 \\
>0.05 \\
>0.05 \\
\text { NA } \\
0.051 \\
>0.05\end{array}$ \\
\hline
\end{tabular}

NA, data not available (discharge $<96$ hours after posterior approach). ${ }^{\star}$ Relative to preceding value. rior approach. A recurrence of symptomatic atrioventricular nodal re-entry tachycardia was, however, seen in 11 of the 23 patients whose treatment had been the anterior approach. Of these, 10 were successfully treated with a second procedure (nine by the anterior and one by the posterior approach), bringing the final success rate in this subgroup to $95 \%$.

\section{ATRIOVENTRICULAR CONDUCTION}

The table shows a complete disclosure of results. PR interval before ablation was normal in all cases, measuring $142(29.5)$ and $144(21 \cdot 2) \mathrm{ms}$ for the groups given treatment by the anterior and posterior approaches respectively. After the anterior approach a significant progressive increase in PR interval was observed up to 48 hours afterwards to a maximum of $282(62 \cdot 2)$ ms. After 48 hours no further significant change in PR interval was observed during the stay in hospital, although a decrease relative to the value at discharge was observed one month after the procedure. At $231(51 \cdot 2) \mathrm{ms}$ this was longer than the $P R$ interval directly after ablation $(P=$ $0.002)$ and shorter than that after 48-96 hours $(P<0.004)$, but it was not significantly different from the PR interval measured 24 hours after the procedure. Six months later PR interval was stable at this value. One case of total atrioventricular block with a junctional escape rhythm developed 24 hours after an uncomplicated procedure without occurrence of second or third degree block during ablation; implantation of a permanent pacemaker was required.

In the group treated by the posterior approach the PR interval reached a slightly yet significantly higher value 24 hours after ablation $(156(22 \cdot 7) \mathrm{ms}, \mathrm{P}=0.004)$. No further significant change was observed during the stay in hospital, and the PR interval at one and six months after the procedure was no longer significantly different from that before ablation. One case of second degree atrioventricular block developed during the first 24 hours after the procedure, although all radiofrequency pulses were delivered at sites without a His bundle deflection and posterior to Koch's triangle. This had spontaneously regressed to a first degree block on follow up (PR interval $240 \mathrm{~ms}, 110 \mathrm{~ms}$ pre-ablation). In this patient third degree atrioventricular block occurred shortly after onset of the first radiofrequency pulse at a site targeted for slow pathway ablation, near the ostium of the coronary sinus. The block lasted $90 \mathrm{~s}$ and was followed by a rapid return of $1: 1$ conduction with a normal $P Q$ interval. Subsequent radiofrequency pulses did not result in a recurrence of this phenomenon.

\section{Discussion}

To our knowledge, no study has systematically documented the delay in atrioventricular conduction after radiofrequency ablation for atrioventricular nodal re-entry tachycardia. Nevertheless, several reports have cited exam- 
ples of late effects on conduction, which suggests that delivery of radiofrequency energy initiates dynamic processes in the atrioventricular node that continue after the patient has left the electrophysiological laboratory. Given the effects of cryoablation, ${ }^{11}$ local factors such as oedema and tissue retraction may be associated with scar formation and lead to delayed effects on conduction.

Both Jazayeri et al and Calkins et al described the occurrence of high degree atrioventricular block one day after ablation with the anterior approach, ${ }^{39}$ as was seen in one of our patients. Lee et al reported one case of third degree atrioventricular block several weeks after ablation. ${ }^{1}$ Similar findings have been reported with the posterior approach. In recent studies by Langberg et al and Wu et al two cases of transient third degree atrioventricular block were reported after the posterior approach. ${ }^{4}$ Occurrences of first degree and Wenckebach block several days after ablation were postulated by Haissaguerre et al to be the result of "progression of tissue lesions." 10

Our results show a progressive increase of PR interval during the first 48 hours after ablation with the anterior approach. Although the interval remained stable during the remaining stay in hospital, it decreased slightly at follow up. Although previous reports have shown a similar, nearly twofold increase in $\mathrm{AH}$ interval directly after ablation, ${ }^{1349}$ information was lacking about atrioventricular conduction during the subsequent days.

After ablation with the posterior approach, a significant if small increase in PR interval was observed 24 hours after the procedure, but this had resolved at follow up. Several studies have reported on AH interval directly after ablation and at restudy several months later, ${ }^{6710}$ but none found any increase in the delay in atrioventricular conduction or a difference between values in the acute phase and at follow up. Again, our results suggest that this may be due to the lack of information about atrioventricular conduction immediately after ablation.

Isolated cases of disturbed atrioventricular conduction after the posterior approach ${ }^{4710}$ underline the possibility of affecting fast pathway conduction by delivery of radiofrequency energy at sites targeting the slow pathway, as is suggested by the prolongation of PR interval 24 hours after ablation in our study. Intraoperative mapping studies by Keim et al and McGuire et al have shown that blocking slow pathway conduction can be achieved over a fairly large distance between the orifice of the coronary sinus and sites more centrally located along the tricuspid annulus.1213 Similarly, activation sequence during fast pathway conduction showed the possibility of an input into the atrioventricular node through either the anterior or the posterior limbus. With a stepwise posterior approach and successively more anterior ablation sites, it is therefore conceivable that a lesion or cumulative effect of lesions may induce tissue effects which encroach upon the zone of fast pathway conduction.

\section{CONCLUSIONS}

We observed progressively delayed atrioventricular conduction until 48 and 24 hours after radiofrequency ablation of atrioventricular nodal re-entry tachycardia by the anterior and posterior approaches respectively. One case of third degree block requiring implantation of a permanent pacemaker occurred 24 hours after an otherwise uncomplicated procedure with the anterior approach. These findings underline the dynamic nature of heart tissue's response to the application of radiofrequency energy; this results in delayed effects on atrioventricular conduction, particularly after the anterior approach. This phenomenon warrants the continuous in hospital monitoring of patients during the first two days after the procedure, particularly if conduction is transiently compromised during the procedure itself.

This study was supported by grant 91.062 from the Netherland Heart Foundation.

1 Lee MA, Morady F, Kadish A, et al. Catheter modification of the atrioventricular junction with radiofrequency of the atrioventricular junction with radiofrequency energy for control of atrioventricular

2 Wu D, Yeh S-J, Wang C-C, et al. Nature of dual atrioventricular pathways and the tachycardia circuit as defined by radiofrequency ablation technique. $\mathcal{F} \mathrm{Am}$ Coll Cardio 1992;20:884-95.

3 Jazayeri MR, Hempe SL, Sra JS, et al. Selective transcatheter ablation of the fast and slow pathways using radiofrequency energy in patients with atrioventricula nodal reentrant tachycardia. Circulation 1992;85 1318-28.

4 Langberg JJ, Leon A, Borganelli $\mathrm{M}$, et al. A randomized, prospective comparison of anterior and posterior approaches to radiofrequency catheter ablation of atrioventricular nodal reentry tachycardia. Circulation 1993; 87:1551-6.

5 Kay GN, Epstein AE, Dailey SM, Plumb VJ. Selective radiofrequency ablation of the slow pathway for the radiofrequency ablation of the slow pathway for the treatment of atrioventricular noda

6 Jackman WM, Beckman KJ, McClelland JH, et al. Treatment of supraventricular tachycardia due to atrioventricular nodal reentry by radiofrequency ablation of slow-pathway conduction. $N$ Engl $\mathcal{f}$ Med 1992;327 313-8.

7 Wu D, Yeh S-J, Wang C-C, Wen M-S, Lin F-C. A simple technique for selective ablation of the slow pathway in atrioventricular node reentrant tachycardia. F $\mathrm{Am}$ Coll Cardiol 1993;21:1612-21.

8 Sung RJ, Huycke EC, Keung EC, Tseng C-D, Lai WT. Atrioventricular node reentry: evidence of reentry and Atrioventricular node Zipes D, Jalife J, eds. Cardiac electrophysiology, from cell to
bedside. Philadelphia: Saunders, 1990:513-25.

9 Calkins H, Sousa J, El-Atassi R, et al. Diagnosis and cure of the Wolff-Parkinson-White syndrome or paroxysmal supraventricular tachycardias during a single electrosupraventricular tachycardias during a single
physiologic test. $N$ Engl $f$ Med 1991;324:1612-8.

10 Haissaguerre M, Gaita F, Fischer B, et al. Elimination of atrioventricular nodal reentrant tachycardia using
of of atrioventricular nodal reentrant tachycardia using
discrete slow potentials to guide application of radiodiscrete slow potentials to guide application
frequency energy. Circulation 1992;85:2162-75.

11 Bakker PFA, Vermeulen FEE, de Boo JAJ, et al. Extensive cryoablation of the left ventricular posterior papillary muscle and subjacent ventricular wall. $\mathcal{f}$ Thorac Cardiovasc Surg 1993;105:327-36.

12 Keim S, Werner $P$, Jazayeri $M$, Akhtar $M$, Tchou $P$. Localization of the fast and slow pathways in atrioventricular nodal reentrant tachycardia by intraoperative ice mapping. Circulation 1992;86:919-25.

13 McGuire M, Bourke JP, Robotin MC, et al. High resolution mapping of Koch's triangle using sixty electrodes in humans with atrioventricular junctional (AV nodal) reentrant tachycardia. Circulation 1993;88:2315-28. 